\title{
PENGARUH PENDAPATAN DAN KECERDASAN SPIRITUAL TERHADAP PERSEPSI ETIS MAHASISWA DENGAN LOVE OF MONEY SEBAGAI VARIABEL INTERVENING
}

\author{
Ahdaf Arridla, Pascasarjana Unesa \\ Ahdaf.ridho.ar@gmail.com
}

\begin{abstract}
ABSTRAK
Penelitian ini bertujuan untuk menganalisis pengaruh pendapatan, jenis kelamin terhadap love of money. dan pengaruh kecerdasan spiritual, jenis kelamin, love of money terhadap persepsi etis mahasiswa. Penelitian ini dilakukan di Fakultas Ekonomi Jurusan Akuntansi Universitas Negeri Surabaya. Jenis penelitian ini adalah kuantitatif deskriptif. Teknik sampling yang digunakan dalam penelitian ini adalah proporsional random sampling. Jumlah sampel yang digunakan berjumlah 146 responden. Analisis data yang digunakan Structural Equation Modeling (SEM). Hasil penelitian menunjukkan bahwa tidak ada pengaruh yang signifikan antara pendapatan terhadap love of money. Ada pengaruh yang signifikan antara kecerdasan spiritual mahasiswa terhadap persepsi etis mahasiswa, dan ada pengaruh yang signifikan antara love of money terhadap persepsi etis mahasiswa.
\end{abstract}

Kata Kunci: Persepsi Etis, Love of Money, Kecerdasan Spiritual, Pendapatan

\begin{abstract}
This study aimed to analyze the influence of income, gender on love of money. and the influence of spiritual intelligence, sex, love of money on ethical perception of students. This research was conducted at the Faculty of Economics, Accounting Department, State University of Surabaya. This type of research is quantitative descriptive. The sampling technique used in this research is proportional random sampling. The number of samples used were 146 respondents. Data analysis Structural Equation Modeling (SEM). The results showed that there was no significant relationship between the income of the love of money. There is a significant relationship between spiritual intelligence of students to the ethical perception of students. and there is significant influence between the love of money against the ethical perception of students.
\end{abstract}

Keywords: Perception Ethical, love of money, spiritual intelligence, income

\section{PENDAHULUAN}

Dewasa ini pandangan masyarakat terhadap profesionalisme akuntan masih sering didiskusikan baik dalam dunia pendidikan seperti universitas. Hal ini disebabkan dengan banyaknya kasus yang menyangkut profesi akuntansi. Beberapa kasus skandal akuntansi yang banyak dibicarakan di dunia adalah kasus transaksi off-balance sheet Enron Energy tahun 2000, kasus peningkatan pendapatan Xerox tahun 1997-2000, kasus manipulasi keuangan Worldcom dansebagainya. Di Indonesia, hal ini pun pernah menjadi isu, seperti antara lain pada kasus mark up laba Kimia Farma tahun 2001, kasus pembukuan ganda Lippo Bank tahun 2002 dan yang terbaru adalah kasus penggelapan pajak yang 
melibatkan pegawai pajak Gayus Halomoan P. Tambunan atau dikenal dengan Gayus Tambunan.

Banyak tanggapan ataupun persepsi masyarakat mengenai fenomena pelanggaran akuntansi yang kemudian menyebabkan timbulnya dilema etis. Contoh pelanggaran dalam hal manajemen laba atau biasa kita sebut earning management. Pada satu sisi, manajemen laba dipandang sebagai suatu tindakan yang seharusnya tidak boleh dilakukan karena dengan adanya manajemen laba infomasi yang diberikan tidak sepenuhnya mencerminkan keadaan perusahaan yang sebenarnya, tetapi cenderung mensamarkan nilai perusahaan sehingga tetap baik dimata stakeholder. Namun disisi lain pelanggaran tersebut dianggap sebagai sesuatu yang wajar dan merupakan tindakan rasional untuk memanfaatkan fleksibilitas dalam ketentuan untuk pelaporan keuangan. Perbedaan persepsi seperti itu dapat terjadi disebabkan oleh lingkungan kerja atau profesi, usia, keyakinan dan ilmu pengetahuan seseorang. Menurut penelitian (Inggarwati dan Arnold 2010) pelaku akuntansi seperti akademisi memandang pelanggaran akuntansi seperti manajemen laba lebih etis dibanding praktisi sementara mahasiswa cenderung lebih menerima pelanggaran tersebut dibandingkan dosen. Oleh karena itu disinilah dibutuhkan pemahaman etika bisnis dan profesi untuk mahasiswa melalui pengembangan kurikulum dengan memberi muatan etika pada mata kuliah, forum-forum diskusi, seminar, maupun peningkatan efektivitas pengajaran. Salah satu penyebab terjadinya pelanggaran etika adalah disebabkan oleh keinginan akan uang. Kita mengetahui bahwa uang merupakan sesuatu yang sangat penting dalam kehidupan sehari-hari, apalagi dalam dunia akuntansi yang erat kaitannya dengan uang. Dalam dunia kerja uang merupakan simbol atau bentuk penghargaan (reward) yang diberikan kepada pekerja. Uang merupakan perangsang untuk giat dalam bekerja sehingga tidak jarang banyak orang melakukan berbagai cara hanya untuk mendapatkan banyak uang.

Tang (1992) memperkenalkan konsep "love of money". Teori tersebut berusaha mengukur perasaan subjektif seseorang tentang uang. Penelitian menunjukkan bahwa love of money terkait dengan beberapa perilaku dalam berorganisasi seperti tingkat kepuasan kerja yang tinggi, tingkat pergantian karyawan yang rendah maupun perilaku organisasi yang tidak baik seperti tindakan kecurangan akuntansi dan lain sebagainya. Tang dan Chiu (2003) berteori bahwa love of money sangat terkait dengan konsep "ketamakan." Mereka menemukan bahwa karyawan Hongkong dengan tingkat love of money yang lebih tinggi kurang puas dengan pekerjaan mereka dibandingkan dengan rekan-rekan mereka. Chen dan Tang (2008) menyatakan bahwa hubungan tersebut dapat menyebabkan perilaku yang tidak etis.

Tang (dalam Pradanti, 2014) menemukan suatu konsep pengukuran yaitu Money Ethic Scale (MES) tujuannya untuk mengukur perasaan subjektif seseorang terhadap uang. Uang seringkali dianggap negatif dalam kehidupan sehari hari, bahkan uang sering dianggap sebagai akar dari kejahatan. Alasannya karena berbagai aksi kejahatan yang terjadi banyak berkaitan dengan uang.

Beberapa penelitian yang menjelaskan hubungan love of money terhadap perilaku individu. Penelitian Luna-Arocas dan Tang (2005) yang menyatakan bahwa kecintaan terhadap uang adalah akar dari segala kejahatan, atau dianggap berhubungan erat dengan konsep ketamakan. Begitu juga Charismawati (2011) menjelaskan semakin besar tingkat kecintaan seseorang terhadap uang 
menyebabkan semakin kecil tingkat persepsi etis orang tersebut ini dikarenakan kecintaan akan uang yang tinggi akan mengakibatkan seseorang menjadi tamak, bahkan tidak jarang karena faktor uang mereka dapat melegalkan berbagai cara yang sudah jelas telah melanggar aturan etika yang ada.

Pada umumnya mahasiswa masih memiliki ketergantungan hidup kepada orangtuanya. Misalnya dalam memenuhi kebutuhan hidup diperkuliahan. Tinggi rendahnya pendapatan (uang saku) mahasiswa dilihat dari status ekonomi orangtuanya. Status ekonomi seseorang memiliki pengaruh terhadap kecintaan terhadap uang yang mereka miliki. Seseorang dengan status ekonomi yang tinggi cenderung lebih menginginkan uang dan memiliki perilaku konsumtif. Status ekonomi kemungkinan besar merupakan pembentuk gaya hidup keluarga misalnya berprilaku konsumtif.Status ekonomi adalah gambaran tentang keadaan seseorang yang ditinjau dari segi ekonomi, contohnya tingkat pendapatan.

Penelitian yang dilakukan oleh Erni (2013) menyatakan bahwa seseorang dengan penghasilan yang tinggi akan memiliki tingkat konsumsi yang tinggi pula, sedangkan seseorang dengan penghasilan rendah cenderung memiliki tingkat konsumsi yang rendah pula. Penghasilan tinggi artinya kepemilikan akan uang sangatlah banyak sehingga seluruh kebutuhan konsumsinya dapat terpenuhi. Prasastianta (2011) menguji faktor yang mendorong perilaku ekonomi, salah satu faktornya adalah status ekonomi mahasiswa. Hasil penelitian tersebut menunjukkan bahwa semakin tinggi status ekonomi seseorang maka ia condong untuk berperilaku konsumtif.

Agamaadalah aspek yang sangat penting dalam menjalani kehidupan sehari-hari. Agama adalah dasar atau pedoman setiap umat manusia dalam bertindak/berprilaku. Baik buruk seseorang dapat dilihat dari latar belakang agamanya.oleh karena itu dibutuhkan pemahaman yang baik tentang agama atau yang biasa kita sebut sebagai kecerdasan spiritual (spiritual quotient / SQ) yang baik. SQ adalah tingkat kecerdasan seseorang yang meliputi kearifan dan prinsip mendasar dari dalam diri seseorang. Dalam mengambil keputusan atau memecahkan masalah, orang yang memiliki SQ yang tinggi tidak hanya akan terpengaruh oleh logika dan emosi, tetapi juga menggunakan pertimbanganpertimbangan yang berasal dari dalam hati.

Ada beberapa penelitian yang dilakukan untuk mengetahui apakah tingkat pengetahuan individu mempengaruhi persepsi etis mahasiswa akuntansi. Misalnya, Tikollah et al., (2006) melakukan penelitian untuk mengetahui pengaruh kecerdasan intelektual, kecerdasan emosional, dan kecerdasan spiritual terhadap persepsi etis mahasiswa akuntansi. Tikollah et al. (2006) menemukan bahwa kecerdasan intelektual secara simultan maupun parsial berpengaruh signifikan terhadap sikap etis mahasiswa akuntansi. Namun, kecerdasan spiritual secara parsial tidak berpengaruh terhadap sikap etis mahasiswa akuntansi (Tikollah et al., 2006). Tingkat pengetahuan yang diteliti pada kali ini adalah kecerdasan spiritual.

Kemudian hasil analisis terhadap 228 responden menunjukkan religiusitas sebagai faktor yang berpengaruh dominan terhadap perilaku etis akuntan, di samping EQ juga sebagai salah satu faktor yang berpengaruh. Semakin tinggi IQ dan SQ individu, maka individu tersebut akan semakin berpersepsi bahwa perilaku tidak etis seperti earningsmanagement adalah praktek yang tidak baik. 
Dengan demikian, tujuan dalam penelitian ini antara lain: untuk menganalisis pengaruh pendapatan, jenis kelamin terhadap love of money. dan pengaruh kecerdasan spiritual, jenis kelamin, love of money terhadap persepsi etis mahasiswa.

\section{METODE PENELITIAN}

Penelitian ini merupakan penelitian kuantitatif yang menggunakan metode deskriptif analisis. Penelitian ini menggunakan tiga variabel bebas yaitu pendapatan (P1), kecerdasan spiritual (SQ). Satu variabel intervening yaitu Love Of Money (LOM), dan satu variabel terikat yaitu persepsi etis (PE).

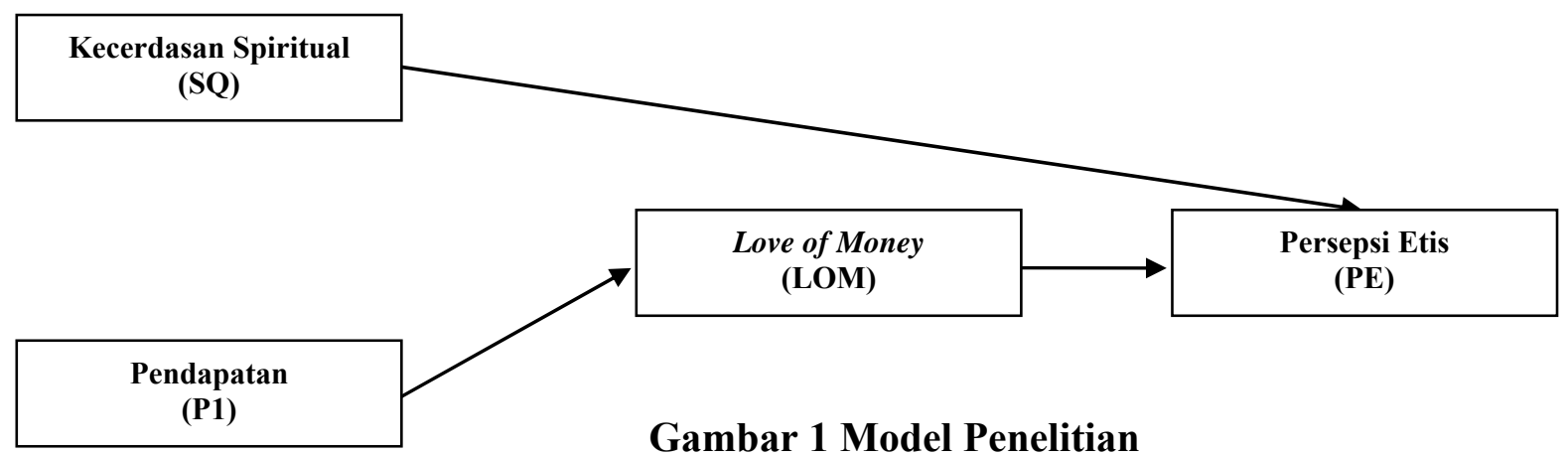

Populasi dalam penelitian ini adalah seluruh mahasiswa program S1 akuntansi dan Pendidikan akuntansi ditambah dengan program Diploma Jurusan Akuntansi Fakultas Ekonomi Universitas Negeri Surabaya angkatan 2012/2013 atau semester 6 yang terdiri dari Diploma Akuntansi 47 responden, S1 Pendidikan Akuntansi 83 responden dan S1 Akuntansi 100 responden. Teknik sampling yang digunakan dalam penelitian ini adalah proporsional random sampling.Teknik pengumpulan data yang digunakan dalam penelitian ini yaitu dengan menggunakan angket. Jenis data yang digunakan dalam penelitian ini adalah data primer. Data yang dikumpulkan langsung dari responden dengan cara penyebaran angket. Instrumen penelitian ini dibangun dari variabel-variabel penelitian dengan sejumlah item tertentu yang dirumuskan berdasarkan indikator setiap variabel yang diadaptasi dan digunakan sebagai rujukan.Kuesioner yang diisi oleh responden dibuat dalam bentuk pertanyaan tertutup, artinya dalam kuesioner sudah ditentukan alternatif pilihan jawaban dari tiap item pertanyaan. Dalam pelaksanaan pengisian nantinya responden hanya memilih salah satu jawaban yang cocok dengan keadan yang dialami responden.Teknik analisis data yang digunakan adalahStructural Equation Modeling (SEM).

SEM adalah suatu teknik analisis statistik untuk menguji dan mengestimasi hubungan kausal dengan mengintegrasikan analisis faktor dan analisis jalur. SEM juga menganalisis hubungan kausal antar variabel eksogen dan endogen yang menunjukan adanya perubahan nilai dari suatu variabel akan menghasilkan perubahan dari variabel lain, di samping itu juga dapat sekaligus untuk memeriksa validitas dan reliabilitas instrumen peneliti. Penelitian ini menggunakan tiga variabel eksogen yaitu pendapatan (P1), kecerdasan spiritual (SQ) dan dua variabel eksogen yaitu Love Of Money (LOM), dan persepsi etis (PE), di mana variabel Love Of Money (LOM) juga sebagai variabel intervening. 


\section{HASIL DAN PEMBAHASAN}

Berdasarkan uji yang digunakan maka dihasilkan hubungan antara indikator dengan variable melalui proses analisis faktor konfirmatori.

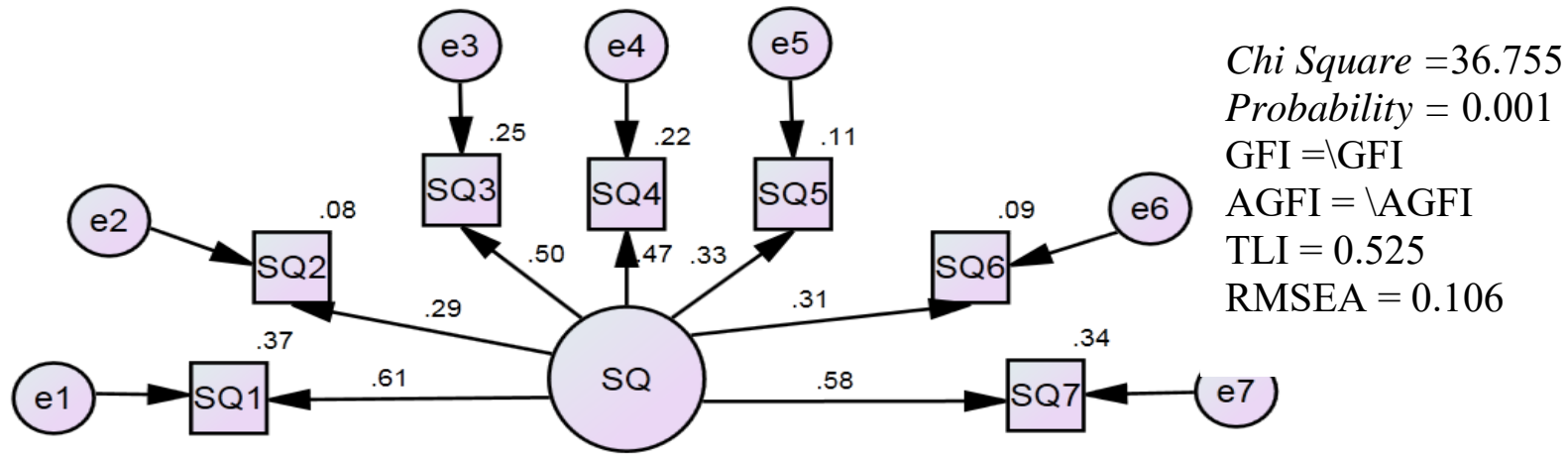

Gambar 2. Hubungan Indikator dengan Variabel Kecerdasan Spiritual Tabel 1

Uji Confirmatory Factor AnalysisVariabel Kecerdasan Spiritual

\begin{tabular}{|ll|rrrrr|}
\hline & & Estimate & S.E. & C.R. & P & Label \\
\hline SQ1 $<---$ & SQ & 1.000 & & & & \\
SQ2 $<---$ & SQ & .517 & .188 & 2.748 & .006 & \\
SQ3 $<---$ & SQ & .922 & .304 & 3.037 & .002 & \\
SQ4 <--- & SQ & .911 & .339 & 2.693 & .007 & \\
SQ5 <--- & SQ & .494 & .187 & 2.649 & .008 & \\
SQ6 $<---$ & SQ & .591 & .257 & 2.298 & .022 & \\
SQ7 <--- & SQ & 1.042 & .211 & 4.947 & $* * *$ & \\
\hline
\end{tabular}

Hasil uji analisis konfirmatori dapat dilihat bahwa semua indikator signifikan dengan nilai signifikansi $<0.05(5 \%)$. Hal ini dapat dilihat dari tabel 4.6 di atas dimana nilai nilai signifikansinya di bawah 0.05 , sehinggga semua indikator dapat digunakan dalam analisis selanjutnya.

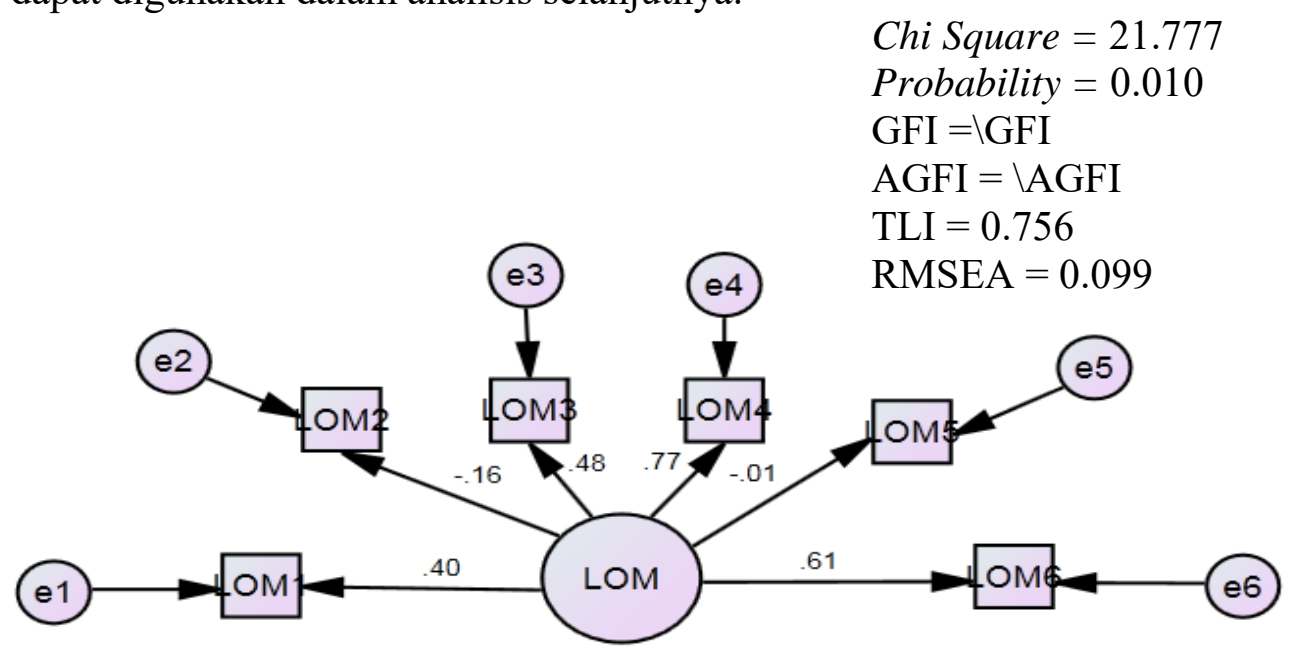

Gambar 3. Hubungan Indikator dengan Variabel Love of Money 
Tabel 2

Uji Confirmatory Factor Analysis Variabel Love Of Money

\begin{tabular}{|ll|rrrrr|}
\hline & & Estimate & S.E. & C.R. & P & Label \\
\hline LOM1 <--- & LOM & 1.000 & & & & \\
LOM2 <--- & LOM & -.487 & .292 & -1.671 & .095 & \\
LOM3 <--- & LOM & 1.721 & .507 & 3.395 & $* * *$ & \\
LOM4 <--- & LOM & 2.555 & .687 & 3.719 & $* * *$ & \\
LOM5 <--- & LOM & -.004 & .243 & -.016 & .087 & \\
LOM6 <--- & LOM & 1.998 & .533 & 3.748 & $* * *$ & \\
\hline
\end{tabular}

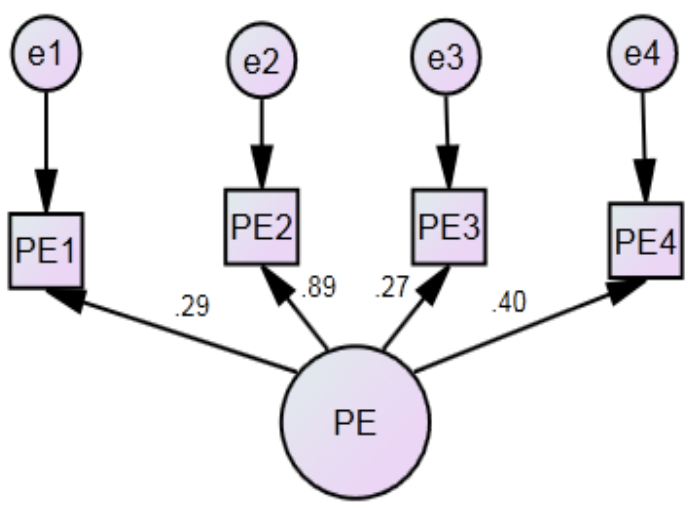

Chi Square $=5.315$

Probability $=0.007$

GFI $=$ GFI

AGFI $=\backslash$ AGFI

$\mathrm{TLI}=0.738$

RMSEA $=0.107$

Gambar 4. Hubungan Indikator dengan Variabel Penelitian

Tabel 3

Uji Confirmatory Factor Analysis Variabel Persepsi Etis

\begin{tabular}{|ll|rrrrl|}
\hline & & Estimate & S.E. & C.R. & P & Label \\
\hline PE1 <--- & PE & 1.000 & & & & \\
PE2 <--- & PE & 2.131 & 1.096 & 1.944 & .052 & par_1 \\
PE3 <--- & PE & .878 & .391 & 2.245 & .025 & par_2 \\
PE4 <--- & PE & 1.100 & .410 & 2.684 & .007 & par_3 \\
\hline
\end{tabular}

Hipotesis pertama dalam penelitian ini adalah diduga ada pengaruh yang signifikan antara kecerdasan spiritual terhadap persepsi etis mahasiswa Universitas Negeri Surabaya. Pengujian hipotesis dilakukan dengan menggunakan Structural Equation Modeling (SEM). Sebelum dilakukan perhitungan untuk menentukan hipotesis terlebih dahulu harus dilakukan pengujian terhadap normalitas data. 


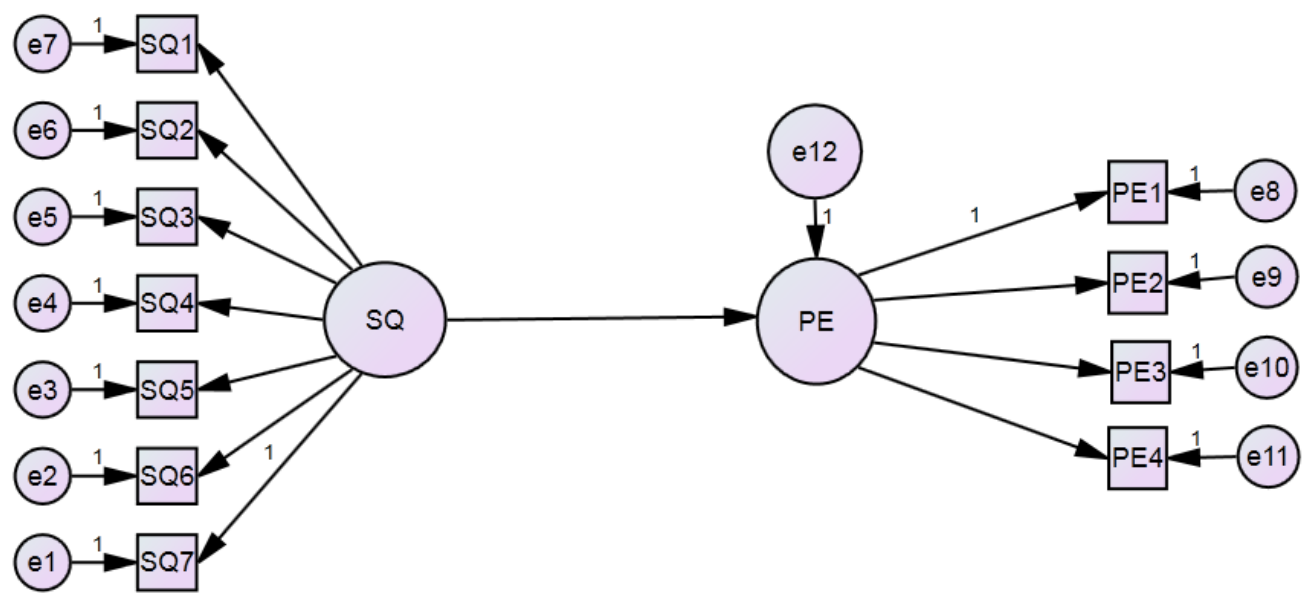

\section{Gambar 5. Model Hubungan Kecerdasan spiritual (SQ) terhadap Persepsi Etis (PE)}

Model diatas menggambarkan pengaruh variabel kecerdasan spiritual (SQ) terhadap persepsi etis mahasiswa (PE). Sedangkan Tabel 5 menunjukan bahwa nilai $P$ adalah 0.057, maka disimpulkan bahwa Kecerdasan spiritual (SQ) berpengaruh terhadap Persepsi etis (PE) mahasiswa. Hasil uji hipotesis dapat dilihat dari tabel berikut ini :

\section{Tabel 5}

Regression Weights

\begin{tabular}{|ll|rcccc|}
\hline & & Estimate & S.E. & C.R. & P & Label \\
\hline PE <--- & SQ & .445 & .234 & 1.905 & .057 & par_10 \\
\hline
\end{tabular}

Adapun kajian yang dapat memperkuat hasil analisis ini seperti yang dijelaskan bahwa kecerdasan spiritual menempatkan perilaku dan hidup manusia dalam konteks makna yang lebih luas dan kaya (Zohar \& Marshall, 2002), yang memungkinkan seseorang untuk menyatukan hal-hal yang bersifat intrapersonal dan interpersonal, serta menjembatani kesenjangan antara diri dan orang lain (Zohar \& Marshall, 2002). Wujud dari kecerdasan spiritual ini adalah sikap moral yang dipandang luhur (baik) oleh pelaku (Ummah dkk, 2003). Hal ini berarti orang yang memiliki kecerdasan spiritual akan mewujudkanya dalam perilaku yang luhur (etis). Orang yang berperilaku baik adalah orang yang memiliki pribadi yang baik, ketika melihat fenomena berupa pelanggaran apapun akan memandang hal tersebut tidak baik.

Hipotesis kedua dalam penelitian ini adalah diduga ada pengaruh yang signifikan antara pendapatan terhadap love of money mahasiswa Universitas Negeri Surabaya. 


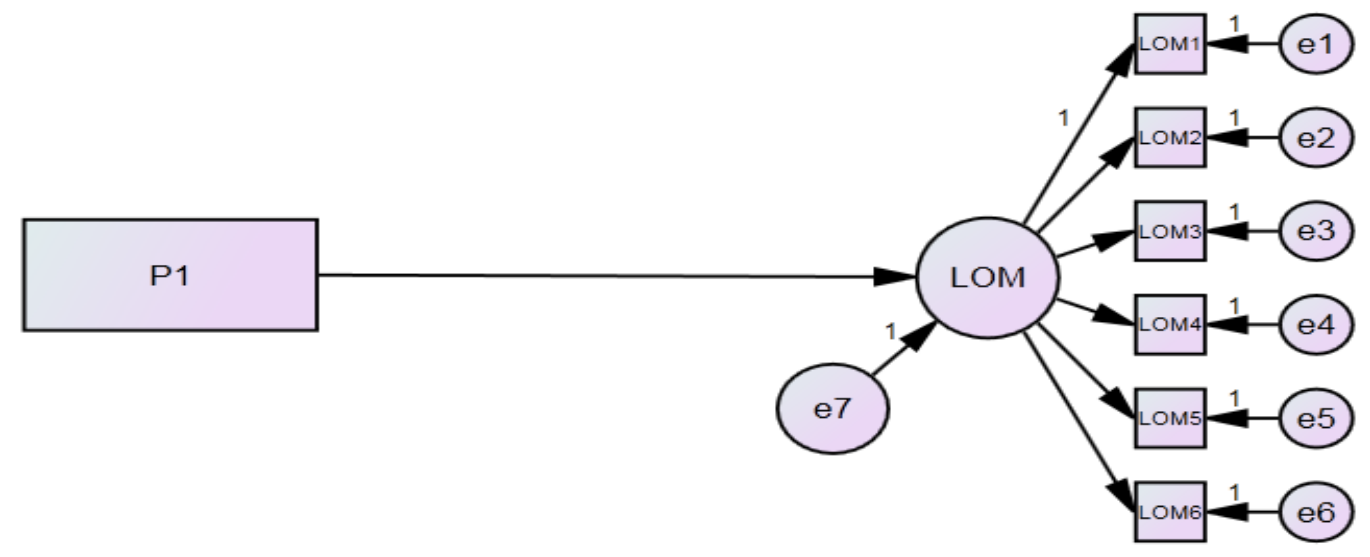

\section{Gambar 6. Model Hubungan Pendapatan (P1) terhadap Love of Money}

\section{(LOM)}

Model diatas menggambarkan pengaruh variabel pendapatan (P1) terhadap love of money mahasiswa (LOM). Sedangkan tabel di bawah ini menunjukan bahwa nilai $\mathrm{P}$ adalah 0.394 maka disimpulkan bahwa pendapatan tidak berpengaruh terhadap love of money.

Tabel 7

Regression Weights

\begin{tabular}{|ll|rcccc|}
\hline & & Estimate & S.E. & C.R. & P & Label \\
\hline LOM <--- & P1 & -.034 & .040 & -.852 & .394 & par_6 \\
\hline
\end{tabular}

Dari hasil analisis penelitian kali ini berbeda dengan penelitian sebelumnya yang mengatakan bahwa status ekonomi dalam hal ini pendapatan memiliki pengaruh terhadap love of money. Seperti yang dikatakan oleh Linton, 1990 (dalam pradanti 2014) Peran uang dalam kehidupan seseorang adalah untuk menopang cara hidup kelas ekonomi tertentu.Kelas ekonomi tertentu bisa dari kalangan pengusaha yang memiliki penghasilan besar bisa juga dari kalangan bawah yang berpenghasilan rendah namun bukan berarti kalangan bawah tidak memiliki kecintaan terhadap uang bahkan bisa jadi memiliki kecintaan uang yang tinggi karena faktor ekonomi yang mendera yang mewajibkan mereka harus mengatur keuangan dengan baik.

Namun hasil penelitian ini sesuai dengan apa yang telah diteliti oleh Pradanti (2014) kepada mahasiswa akuntansi di Universitas Diponogoro yang mengatakan bahwa latar belakang ekonomi mahasiswa tidak mempengaruhi love of money. Menurut Tang (2005) menjelaskan bahwa pendapatan yang tinggi mempengaruhi gaya hidup seseorang. Gaya hidup dapat dicontohkan gemar berbelanja yang identik dengan sebutan konsumtif. Tidak hanya orang kaya dengan penghasilan tinggi yang gemar berbelanja namun orang yang berpenghasilan rendahpun gemar berbelanja.

Hipotesis ketiga dalam penelitian ini adalah diduga ada pengaruh yang signifikan antara love of money berpengaruh terhadap persepsi etis mahasiswaUniversitas Negeri Surabaya. Tabel di bawah menunjukan bahwa nilai 
$\mathrm{P}$ adalah 0.049 maka disimpulkan bahwa love of money berpengaruh terhadap persepsi etis mahasiswa.

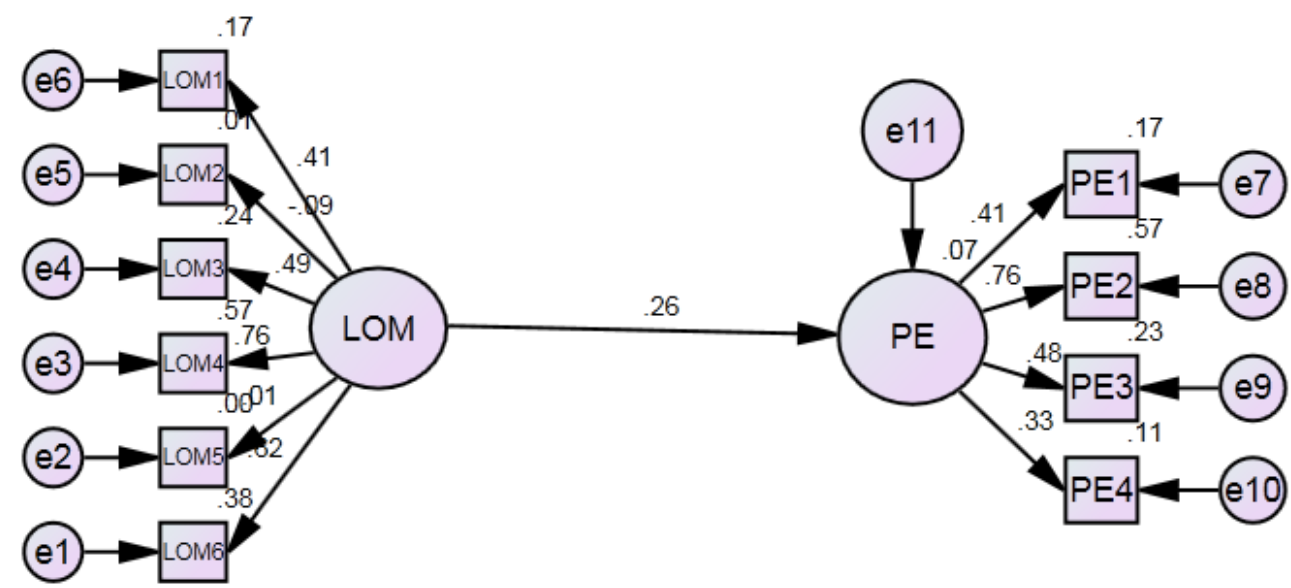

\section{Gambar 9. Model Hubungan Love of Money (LOM) terhadap Persepsi etis (PE)}

Model diatas menggambarkan pengaruh variable love of money (LOM) terhadap persepsi etis (PE) mahasiswa.

Tabel 13

Regression Weights

\begin{tabular}{|c|c|c|c|c|}
\hline & Estimate & S.E. & C.R. & $\mathrm{P}$ \\
\hline PE <--- LOM & .203 & .112 & 1.821 & 049 \\
\hline
\end{tabular}

Penelitian Tang et al. (2000) menemukan bahwa seseorang dengan love of money yang rendah memiliki kepuasan kerja yang rendah. Love of money memiliki pengaruh terhadap persepsi etis. Semakin tinggi tingkat love of money yang dimiliki seseorang, maka akan semakin rendah persepsi etis yang dimilikinya, begitu pula sebaliknya. Hal ini disebabkan karena apabila seseorang memiliki kecintaan uang yang tinggi, maka ia akan berusaha untuk melakukan segala cara agar kebutuhannya terpenuhi walaupun tidak sesuai dengan etika. Hubungan antara perilaku cinta uang dan persepsi etis telah diteliti lebih lanjut di beberapa negara. Elias (2010) menguji hubungan love of money apabila dikaitkan dengan persepsi etis menghasilkan hubungan yang negatif.

Hasil t hitung koefisien tidak langsung sebesar $0.61311<$ nilai $\mathrm{t}$ tabel $(1,96)$. Hal ini menunjukan bahwa pengaruh Pendapatan (P1) terhadap Persepsi Etis (PE) melalui Love of Money (LOM) sebesar 0.61311 tidak signifikan. Perhitungan nilai koefisien pengaruh tidak langsung dilakukan dengan mengalikan koefisien-koefisien pengaruh langsung yang terdapat di sepanjang jalur yang menghubungkan kedua variabel (Dachlan, 2014). Maka perhitunganya $0.026 \times(0.613)=0.0159$. Dari perhitungan tersebut dapat diartikan bahwa pengaruh langsung pendapatan sebesar 0.026, namun hanya sebagian dari pengaruh tersebut, yaitu 0.0159 dari 0.026 , yang diteruskan ke persepsi etis. 
Koefisien pengaruh tidak langsung sebesar 0.0159 yang dapat diartikan bahwa persepsi etis akan turun sebesar 0.0159 untuk setiap kenaikan pendapatan sebesar 1 satuan setelah melalui mediasi pada Love of Money.

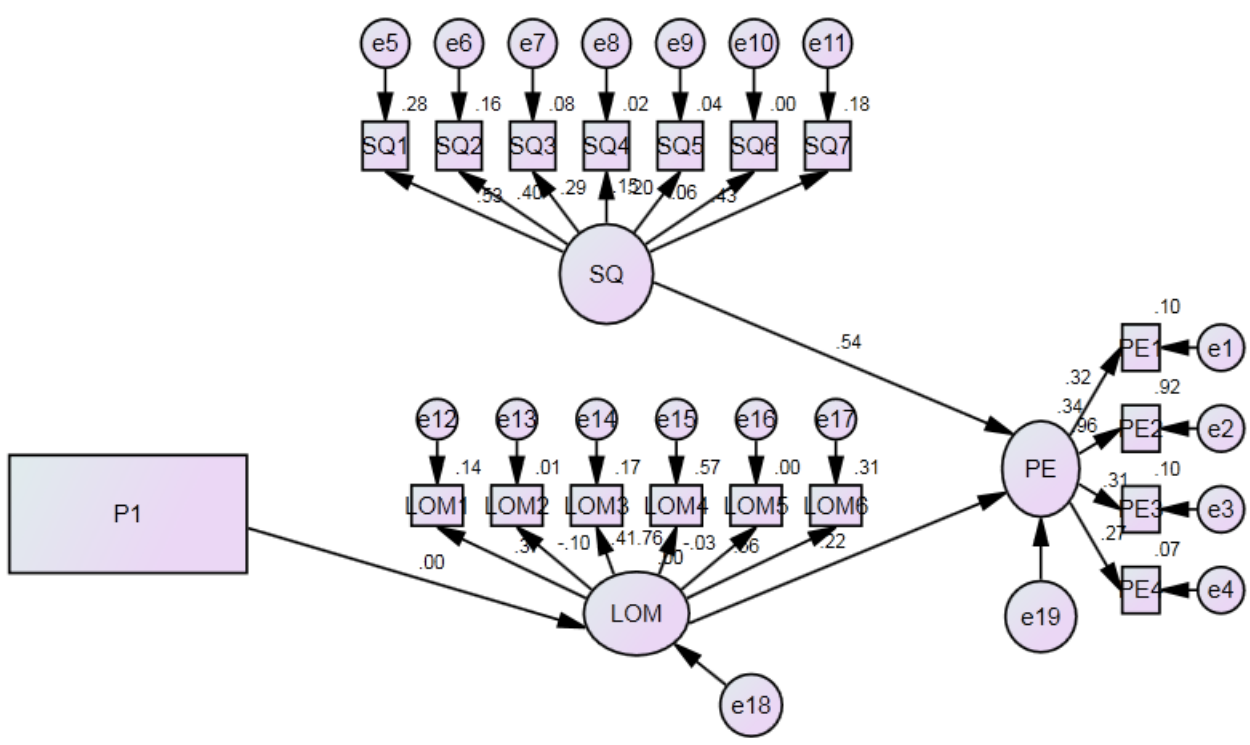

Gambar 10

Model Penelitian

Model diatas menggambarkan pengaruh seluruh variabel. Dari hasil output maka didapatkan kriteria Goodnes of fit sebagai berikut:

Tabel 8

Kriteria Goodnes of fit

\begin{tabular}{|c|c|c|c|}
\hline $\begin{array}{c}\text { Goodness of fit } \\
\text { Index }\end{array}$ & Cut off value & Hasil model & Keterangan \\
\hline Chi square & diharapkan kecil & 199.878 & Kurang Baik \\
\hline Probability & $<0,05$ & 0.000 & Baik \\
\hline RMSEA & $<0.08$ & 0.059 & Baik \\
\hline GFI & $>0.90$ & 0.907 & Baik \\
\hline AGFI & $>0,80$ & 0.828 & Baik \\
\hline TLI & $>0,90$ & 0.617 & Kurang Baik \\
\hline CFI & $>0,90$ & 0.667 & Kurang Baik \\
\hline
\end{tabular}

Dari hasil perhitungan di atas dapat diketahui bahwa nilai Chi Square, TLI $<$ dari 0,90, CFI $<$ dari 0,90 sehingga dikatakan kurang baik tetapi nilai dari Goodness of fit Probability, GFI, dan AGFI telah memenuhi kriteria fit yaitu diatas 0,90 sedangkan RMSEA juga memenuhi kriteria fit yaitu kurang dari 0,08 sehingga dapat dikatakan model dapat diterima.

\section{SIMPULAN}

Terdapat pengaruh yang signifikan antara kecerdasan spiritualterhadap persepsi etis mahasiswa akuntansi Universitas Negeri Surabaya. Artinya ada hubungan 
yang positif antara kecerdasan spiritual dengan persepsi etis yaitu semakin baik tingat kecerdasan spiritual mahasiswa maka persepsi etis terhadap pelanggaran akuntansi semakin baik. Tidak terdapat pengaruh antara pendapatan terhadap love of money mahasiswa akuntansi Universitas Negeri Surabaya. Artinya berapapun besarnya pendapatan mahasiswa tidak berpengaruh terhadap sifat love of money seseorang. Terdapat pengaruh yang signifikan antara love of money terhadap persepsi etis mahasiswa akuntansi Universitas Negeri Surabaya. Artinya semakin besar cinta uang mahasiswa maka persepsi etis mahasiswa atas suatu pelanggaran menjadi kecil. Untuk penelitian selanjutnya agar menambah jumlah responden, terutama responden yang sudah bekerja dan berkeluarga seperti mahasiswa Pascasarjana Jurusan Akuntansi atau pihak akedemisi seperti dosen akuntansi harapannya disamping jumlah responden semakin banyak juga agar model yang dihasilkan dapat mewakili populasi. Kemudian memperhatikan proporsionalitas jenis kelamin responden harapannya agar hasil penelitian berikutnya dapat meminimalkan bias gender.

\section{DAFTAR RUJUKAN}

Erni, Riza. (2013). Pengaruh Pembelajaran Ekonomi dan Status Sosial Ekonomi terhadap PerilakuKonsumsi. Skripsi

Inggarwati K., dan Kaudin, A. (2010). Persepsi Etis Pelaku Akuntansi TerhadapPraktik Manajemen Laba Berdasarkan Profesi. Jurnal Manajemen Teori dan Terapan. Tahun 3 No. 3

Prasastianta, Dian. (2011).Pengaruh Minat Pada Pelajaran Ekonomi, Status Sosial Ekonomi Orang Tua, Pengetahuan Ekonomi Dan Rasionalitas Ekonomi Terhadap Perilaku Ekonomi.Skripsi

Tang, T. (1992). "The Meaning of Money Revisited",. Journal of Organizational Behavior, Vol. 13, pp. 197-202.

Tang, T., and Chen, Y. (2008). Intelligence vs. Wisdom: The Love of Money, Machiavellianism,and Unethical Behavior across College Major and Gender. Journal of Business Ethics, 82 (1), 1-26.

Tang, T., \& Chiu, R. (2003). "Income, money ethics, pay satisfaction, commitment, and unethical behavior: is the love of money the root of evil for Hong Kong employees?'. Journal of Business Ethics, Vol. 46, pp. 1330.

Tang, T., Tillery, K., Lazarevski, B., \& Luna-Arocas, R. (2004). "The love of money and work related attitudes: money profiles in Macedonia". Journal of Managerial Psychology, Vol. 19 No. 5 , pp. 542-8.

Tang, T., Tang, D., \& Luna-Arocas, R. (2005). "Money profiles: the love of money, attitudes, and needs”. Personnel Review, Vol. 34 No. 5, pp. 60324.

Tikollah, Ridwan M., Triyuwono, Iwan., Ludigdo, Unti. (2006). "Pengaruh kecerdasan emosional, kecerdasan intelektual, kecerdasan spiritual terhadap sikap etis mahasiswa akuntansi”. SNA IX, Padang, 23-26 Agustus. 